\title{
Review of "Forensic Entomology"
}

\author{
Carlos Henrique Marchiori
}

1 Ins tituto Federal Goiano

Forensic Entomology - the study of insects and other arthropods associated with various criminal issues - serves as an auxiliary tool, for example, in investigating crimes against victims of violent death.

The science of Forensic Entomology is multidisciplinary. It involves the fields of insect taxonomy, physiology, genetics, acarology, population dynamics, ecology, and statistics. Although entomological evidence is most often use to establish a portion of the postmortem interval in human and animal death, it often involves food product contamination cases, and urban Entomology. Utilize this website as a reference as you explore the science behind Forensic Entomology (https://www.forensicentomology.com/).

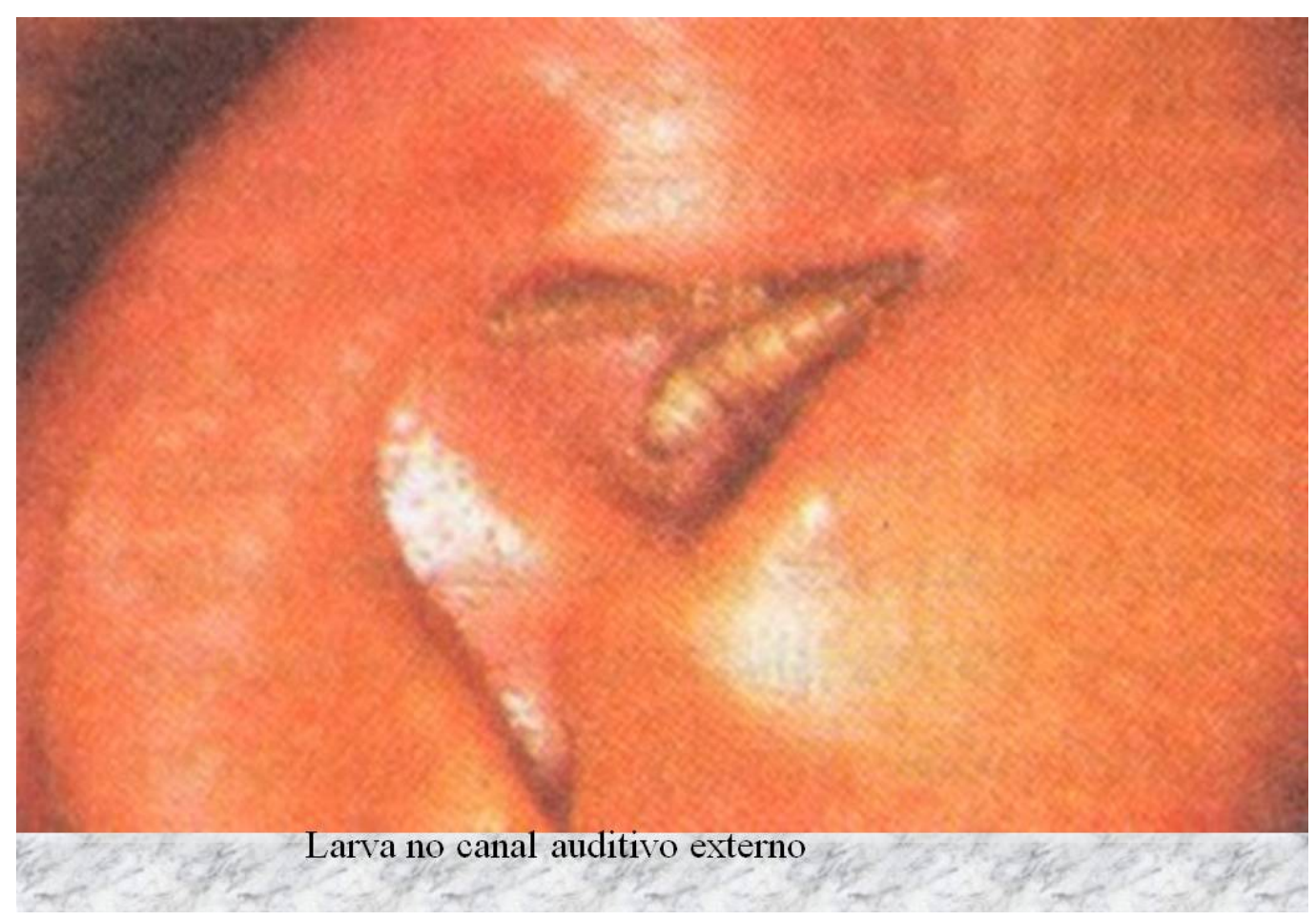

Caption 


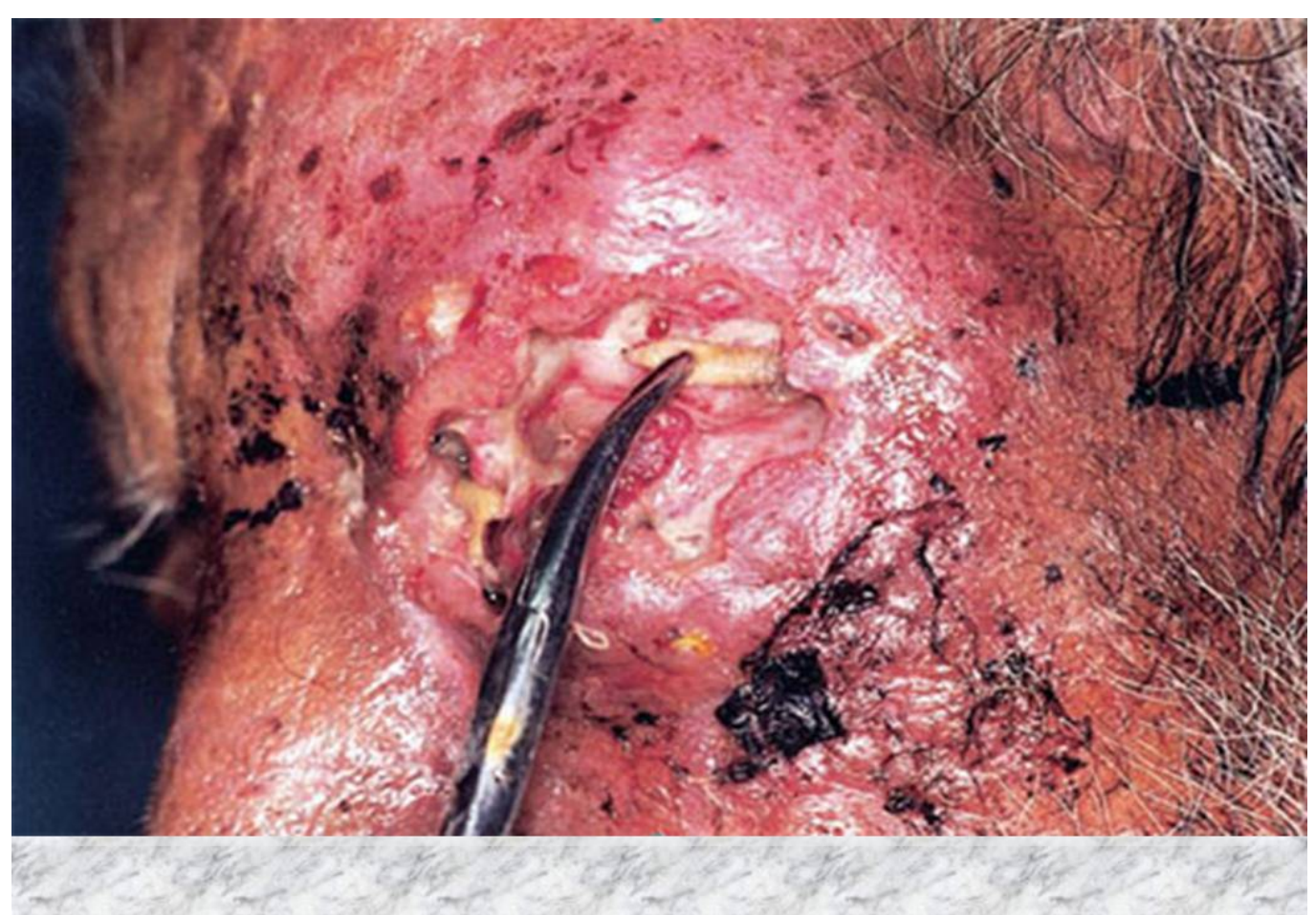

Caption 